\title{
Impact of Solar Control PVB Glass on Vehicle Interior Temperatures, Air-Conditioning Capacity, Fuel Consumption, and Vehicle Range
}

\author{
John Rugh, Larry Chaney, Laurie Ramroth and Travis Venson \\ National Renewable Energy Laboratory \\ Matthew Rose \\ Eastman Chemical
}

\begin{abstract}
The objective of the study was to assess the impact of a Saflex ${ }^{1}$ S Series solar control PVB (polyvinyl butyral) windshield on conventional vehicle fuel economy and electric vehicle (EV) range. The approach included outdoor vehicle thermal soak testing, RadTherm cooldown analysis, and vehicle simulations. Thermal soak tests were conducted at the National Renewable Energy Laboratory's Vehicle Testing and Integration Facility in Golden, Colorado. The test results quantified interior temperature reductions and were used to generate initial conditions for the RadTherm cooldown analysis. The RadTherm model determined the potential reduction in air-conditioning $(\mathrm{A} / \mathrm{C})$ capacity, which was used to calculate the $\mathrm{A} / \mathrm{C}$ load for the vehicle simulations. The vehicle simulation tool identified the potential reduction in fuel consumption or improvement in EV range between a baseline and solar control PVB configurations for the city and highway drive cycles. The thermal analysis determined a potential $4.0 \%$ reduction in $\mathrm{A} / \mathrm{C}$ power for the solar control PVB configuration. The reduction in $\mathrm{A} / \mathrm{C}$ power improved the vehicle range of EVs and fuel economy of conventional vehicles and plug-in hybrid electric vehicles.
\end{abstract}

\section{INTRODUCTION}

Continued volatile oil prices have automakers increasingly focused on improving fuel consumption. Additionally, global environmental regulations such as U.S. Corporate Average Fuel Economy (CAFE) standards and European Directives provide a regulatory framework, which continue to challenge the automotive industry to meet improved fuel economy and/or meet carbon dioxide $\left(\mathrm{CO}_{2}\right)$ emissions standards. As powertrains become electrified, climate control loads reduce range or cause the gasoline engine to operate more frequently. If the thermal loads of the vehicle can be reduced, and correspondingly air-conditioning $(\mathrm{A} / \mathrm{C})$ usage and compressor power, the electric vehicle (EV) range with $\mathrm{A} / \mathrm{C}$ on can be increased. If the battery is sized to account for the energy to operate the $\mathrm{A} / \mathrm{C}$ system, reducing the thermal loads may decrease the battery size and cost and reduce vehicle weight.

Automotive windshields provide occupant visibility yet also enable the sun's energy to enter and build up inside the vehicle-more than $40 \%$ of heat transmitted into a vehicle enters via the windshield. Laminated windshields consist of two pieces of glass held together by a polyvinyl butyral (PVB) interlayer forming a strong bond that tends to stay together even after breakage occurs. For decades, PVB usage has been mandated in windshields by National Highway Traffic and Safety Administration (NHTSA) and the international community for safety reasons, however, advanced laminated glazings have increasingly been utilized by original equipment manufacturers (OEMs) to improve fuel efficiency and reduce $\mathrm{CO}_{2}$ remissions while enhancing occupant comfort. In addition to providing traditional safety benefits of automotive laminated glazing, solar control interlayers absorb infrared (IR) wavelengths that were previously transmitted through the vehicle's glazings, which reduce air-conditioning usage and improves vehicle fuel economy and $\mathrm{CO}_{2}$ emissions.

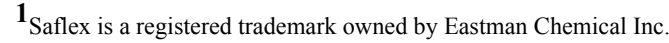


Thermal load reductions due to advanced glazings have been previously researched by the National Renewable Energy Laboratory (NREL) $[\underline{1}, \underline{2}, \underline{3}]$. The work discussed in this paper adds to the previous research by testing the impacts of absorbing PVB. Also a new vehicle simulation software (FASTSim) was used to determine the impact of reduced A/C compressor power on three types of vehicles (conventional, PHEV, and EV). The thermal analysis process was improved by the addition of a

- highly detailed thermal model,

- thermodynamic model to convert the convert change in vent temperature to a change in $\mathrm{A} / \mathrm{C}$ capacity including the impact of humidity, and

- improved compressor power input to the vehicle simulation software.

A common question regarding solar control glazings is, "Will thermal comfort be impacted in the winter?" The design case for cabin heating is driving at night (no solar load); therefore, if the heating system is designed properly, thermal comfort will not be impacted by glazing optical properties.

In a conventional vehicle, waste heat from the engine heats the cabin. Glazing does not impact winter fuel economy. In an EV, battery energy heats the cabin and reduces vehicle range. The following characteristics of the environment combine to minimize the solar load in the winter and the impact of glazing properties on range:

1. low sun angle and low solar intensity,

2. less daylight hours, and

3. fewer sunny days.

\section{APPROACH}

The objective of the testing and analysis program was to determine the impact of a solar control PVB windshield on interior temperatures, $\mathrm{A} / \mathrm{C}$ power, and vehicle performance (fuel use and range).

An outdoor thermal soak test was performed on two vehicles to determine the reduction (or increase) in temperatures due to the solar control PVB windshield. NREL then performed a thermal analysis to determine the impact on $\mathrm{A} / \mathrm{C}$ system capacity. The test results were used set up the steady-state thermal soak simulations and initialize the cooldown simulations. The resulting reduction in $\mathrm{A} / \mathrm{C}$ capacity was used to reduce the $\mathrm{A} / \mathrm{C}$ power in the vehicle performance model which provided fuel use and range impacts. An overview of the approach is shown in Figure 1.

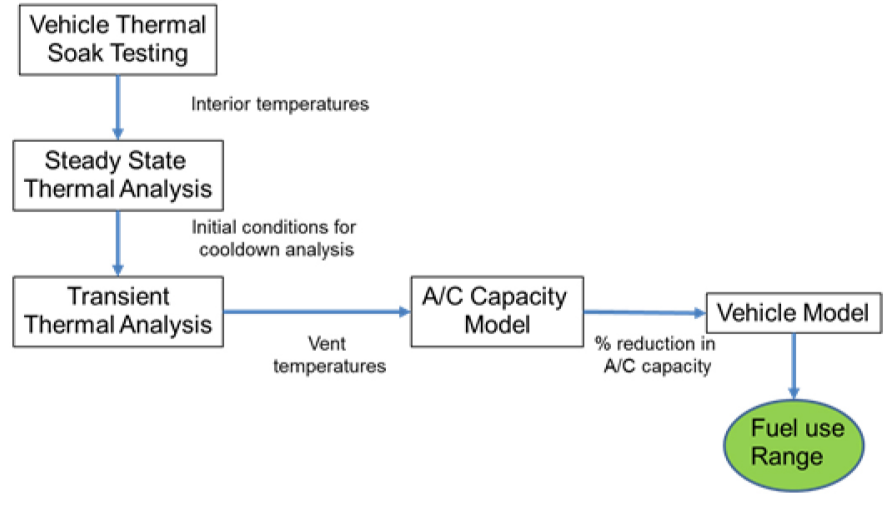

Figure 1. Overview of test and analysis approach

\section{VEHICLE TESTING}

A vehicle test program consisted of two vehicles: a control vehicle and a test vehicle. Thermal soak tests were conducted on each vehicle to quantify vehicle interior temperature distributions resulting from solar loading and outdoor ambient conditions. During the thermal soak test procedure, the engines were off to simulate parked car conditions. The windows were closed to replicate how people commonly park their vehicles due to security, dust, and rain concerns. The vehicles were oriented south and located away from any shading structures to maximize solar loading. If the vehicles were oriented in a different direction, the measured impact of modifying the windshield would have been less. Since a vehicle can be parked/driven in any orientation with respect to the sun and absorbing treatments can be incorporated on any window, this test and analysis determined the impact of improving the optical properties of the window most likely to impact driver thermal comfort at a sun position most likely to impact the thermal load. Weather conditions were monitored, and "repeatable test days" were defined as days with average solar irradiance more than $700 \mathrm{~W} / \mathrm{m}^{2}$ and average wind speeds less than $3 \mathrm{~m} / \mathrm{s}$.

The control vehicle was simultaneously soaked alongside the test vehicle to account for variances in weather conditions between test days. Each vehicle's response to ambient conditions was characterized across four baseline days. The inherent temperature differences between the two vehicles were calculated. With this information, we were able to calculate what the interior temperatures of the test vehicle would have been if we had not modified the windshield. Prior to baseline testing, the OEM windshields in both vehicles were replaced with green tint windshields of known optical properties $(\mathrm{Tts}=62 \%)$. Once the baseline testing was completed, the Saflex S Series solar control PVB windshield (Tts $=55 \%)$ was installed in the test vehicle. 


\section{Test Setup}

Experiments were conducted at NREL's Vehicle Testing and Integration Facility (VTIF), shown in Figure 2, during September 2011. The facility is located in Golden, Colorado, at an elevation of 5,997 feet at latitude $39.7 \mathrm{~N}$ and longitude $105.1 \mathrm{~W}$. Table 1 summarizes the average weather conditions between 12:30 and 13:30 MDT for each configuration. Given the potential variation in weather conditions, the solar irradiance and ambient temperature were remarkably close for the two configurations.

Table 1. Summary of weather conditions for the vehicle test

\begin{tabular}{|l|c|c|c|c|c|}
\hline Configuration & $\begin{array}{c}\text { Average } \\
\text { Irradiance }\end{array}$ & \multicolumn{2}{|c|}{$\begin{array}{c}\text { Average } \\
\text { Ambient } \\
\text { Temperature }\end{array}$} & \multicolumn{2}{|c|}{$\begin{array}{c}\text { Average } \\
\text { Wind } \\
\text { Speed }\end{array}$} \\
\hline & $\mathrm{W} / \mathrm{m}^{2}$ & ${ }^{\circ} \mathrm{C}$ & ${ }^{\circ} \mathrm{F}$ & $\mathrm{m} / \mathrm{s}$ & $\mathrm{mph}$ \\
\hline Baseline & 776 & 24.7 & 76.5 & 2.2 & 4.9 \\
\hline Solar PVB & 736 & 23.2 & 73.8 & 2.0 & 4.5 \\
\hline
\end{tabular}

The test and control vehicles were 2011 Toyota Corollas, both the same color to minimize variance in response between vehicles due to solar loading. White vehicles were selected to improve the ability of measuring an impact due to a small change in windshield optical properties. Since exterior color has a second order effect on interior temperatures [ $\underline{3}$ ], the authors do not feel the choice of vehicle color excessively influenced the results. The vehicles shown in Figure 2 were separated by a distance of 15 feet to minimize cross-shadowing and reflective effects. The interiors were light grey with charcoal trim. Each was instrumented with 32-type-k thermocouples. Each thermocouple was calibrated in a National Institute of Standards and Technology-traceable calibration bath with a maximum measurement uncertainty, $\mathrm{U}_{95}$, of $\pm 0.36^{\circ} \mathrm{C}$ (calculated using ASME Standard PTC 19.1-2005). Surface thermocouples were attached using OMEGABOND 101 thermally conductive epoxy. Accuracy of air temperature measurements was maximized by shielding each air thermocouple with radiation shields.

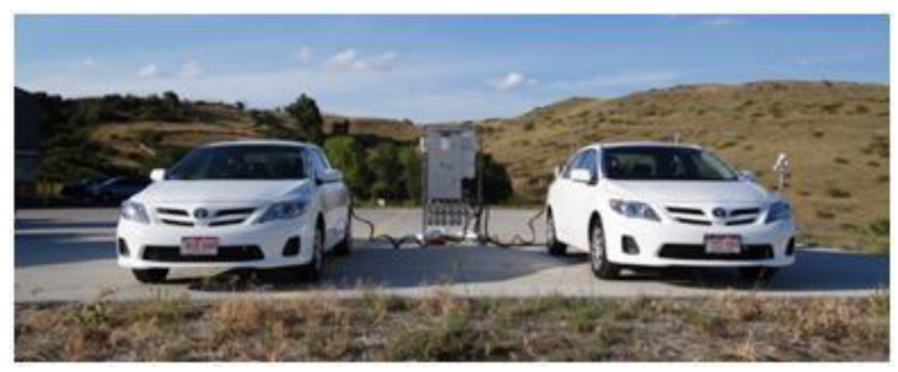

Figure 2. Test setup
The data acquisition system recorded data every minute throughout the day. The difference in temperature (control vehicle versus test vehicle) was then computed for each location. The time period from 12:30 to 13:30 was determined to be the critical period because the temperature differences between the vehicles were fairly constant during this time. The interior air temperature above ambient was also fairly constant during this time. The average reduction in temperature for a given day is the time average from 12:30-13:30.

\section{Test Results}

After a series of baseline tests were conducted to determine the inherent differences between the two vehicles, a solar control PVB windshield was installed in the test vehicle, and temperatures were measured for four test days. Repeatable temperature reductions were observed as reported in Figure 3. The variability in results between the test days was primarily due to changes in ambient weather conditions. As expected, the enhanced absorptive properties the solar control PVB windshield caused the windshield temperature to increase (negative reduction) after installation. This led to an average steering wheel temperature reduction of $5.3^{\circ} \mathrm{C}$ and dashboard reduction of $3.5^{\circ} \mathrm{C}$. The air temperatures were reduced by $1.2^{\circ} \mathrm{C}$ at breath level and $0.9^{\circ} \mathrm{C}$ at the foot level.

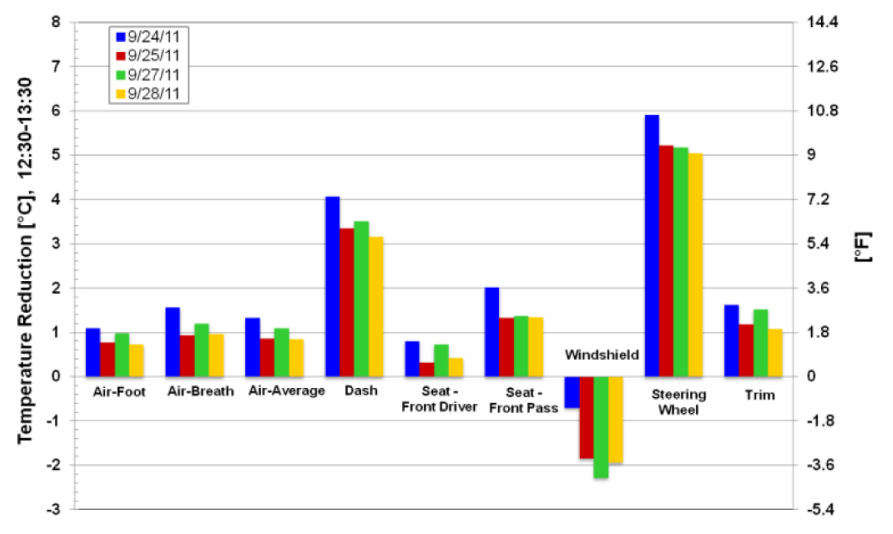

Figure 3. Solar control PVB temperature reductions

The average vehicle temperature reductions are summarized in Table 2. Average air temperatures decreased by $1.0^{\circ} \mathrm{C}$ for solar control PVB. Interior surfaces with incident solar load, such as the dashboard and steering wheel, had larger reductions. A vehicle equipped with this technology will reduce the cabin soak temperature on a hot, sunny day. Cooler cabin temperatures can improve occupant comfort, reduce cooldown time, and lead to less demanding operation of the $\mathrm{A} / \mathrm{C}$ system. 
Table 2. Summary of average temperature reductions

\begin{tabular}{|l|c|c|}
\hline Location & \multicolumn{2}{|c|}{$\begin{array}{c}\text { Temperature Reduction, Solar } \\
\text { Control PVB }\end{array}$} \\
\hline & ${ }^{\circ} \mathrm{C}$ & ${ }^{\circ} \mathrm{F}$ \\
\hline Air-Foot & 0.9 & 1.6 \\
\hline Air-Breath & 1.2 & 2.1 \\
\hline Air-Average & 1.0 & 1.9 \\
\hline Dashboard & 3.5 & 6.3 \\
\hline Front Driver Seat & 0.6 & 1.0 \\
\hline Front Passenger Seat & 1.5 & 2.7 \\
\hline Windshield & -1.7 & -3.0 \\
\hline Steering Wheel & 5.3 & 9.6 \\
\hline Trim & 1.4 & 2.4 \\
\hline
\end{tabular}

\section{THERMAL ANALYSIS}

The purpose of the thermal analysis was to quantify the reduction in $\mathrm{A} / \mathrm{C}$ power that resulted from lowering vehicle interior soak temperatures by using solar control PVB. The approach taken was similar to that used in a previous analysis that was presented by NREL at the 2007 SAE World Congress [ $[3]$. Thermal analysis was used to determine the change in $\mathrm{A} / \mathrm{C}$ vent temperature in a modified vehicle that would achieve the same cooldown time as the baseline (unmodified) vehicle. The reductions in $\mathrm{A} / \mathrm{C}$ capacity and compressor power due to the change in $\mathrm{A} / \mathrm{C}$ vent temperature were calculated. The reduction in $\mathrm{A} / \mathrm{C}$ compressor power was then input into a vehicle simulation that calculates the change in fuel use or electric range due to the reduction in $\mathrm{A} / \mathrm{C}$ compressor power.

\section{RadTherm Analysis Methodology}

The thermal model included a numerical representation of a passenger compartment. The thermal analysis tool used for this analysis was RadTherm from ThermoAnalytics, Inc. In this type of analysis, the heat transfer between the interior and environment is calculated. Inputs to the model include vehicle geometry, material properties, including glass properties, and environmental (weather) data.

NREL used an existing model of a small sedan that was similar to this project's test vehicle. The model was validated using data from previous extensive thermal soak testing conducted at NREL. The glass properties used in the model were provided by Eastman Chemical and are shown for reference in Table 3. The environmental conditions (solar irradiance, sun position, wind) were obtained from the NREL weather station on $9 / 10 / 11$. The dry-bulb temperature in the analysis was maintained at $35^{\circ} \mathrm{C}$ to simulate a constant hot ambient condition. Heat transfer coefficients on the interior surfaces were computed during previously conducted computational fluid dynamics (CFD) simulations and then mapped to the RadTherm model. In the RadTherm model, the cabin air was represented by a simplified 12-node fluid model and the interior represented by 237 mass nodes. Energy was transferred from the interior surfaces to the air nodes by convection. Energy was also conducted between the interior surfaces and exterior surfaces by conduction. The direction of the heat transfer was determined by the interior and exterior surface temperatures. To allow for a proper transient analysis, the model included thermal mass and temperature distribution within each layer. Flow between the air nodes was calculated by previous CFD simulations and input to the RadTherm model.

Table 3. Glass properties

\begin{tabular}{|c|c|c|c|c|c|}
\hline \multirow[b]{2}{*}{ Config. } & \multirow[b]{2}{*}{ Location } & \multirow[b]{2}{*}{$\begin{array}{c}\text { Glazing } \\
\text { Type }\end{array}$} & \multirow{2}{*}{$\begin{array}{c}\text { Trans. } \\
\text { Solar } \\
\text { weighted } \\
(\%)\end{array}$} & \multirow{2}{*}{$\begin{array}{c}\text { Abs. } \\
\text { Solar } \\
\text { weighted } \\
(\%)\end{array}$} & \multirow{2}{*}{$\begin{array}{r}\begin{array}{r}\text { Thick } \\
\text { ness }\end{array} \\
\text { (mm) }\end{array}$} \\
\hline & & & & & \\
\hline \multirow{4}{*}{ Baseline } & windshield & $\begin{array}{l}\text { Eastman } \\
\text { Chemical } \\
\text { baseline } \\
\text { (standard } \\
\text { PVB) }\end{array}$ & 53.61 & 39.49 & 5.5 \\
\hline & $\begin{array}{l}\text { sidelite- } \\
\text { front }\end{array}$ & OEM & 43.7 & 50.9 & 4 \\
\hline & sidelite-rear & OEM & 43.7 & 50.9 & 4 \\
\hline & backlite & OEM & 43.7 & 50.9 & 4 \\
\hline \multirow{4}{*}{$\begin{array}{l}\text { Solar } \\
\text { Control } \\
\text { PVB }\end{array}$} & windshield & $\begin{array}{l}\text { Saflex } \\
\text { solar } \\
\text { control } \\
\text { PVB }\end{array}$ & 39.23 & 54.32 & 5.5 \\
\hline & $\begin{array}{l}\text { sidelite- } \\
\text { front }\end{array}$ & OEM & 43.7 & 50.9 & 4 \\
\hline & sidelite-rear & OEM & 43.7 & 50.9 & 4 \\
\hline & backlite & OEM & 43.7 & 50.9 & 4 \\
\hline
\end{tabular}

\section{Steady-State Simulation}

Two types of RadTherm simulations were performed: steadystate and transient cooldown. The purpose of the steady-state simulation was to initialize the passenger compartment temperatures for the cooldown simulation. The steady-state temperatures were compared to soak test data and minor adjustments were made to model parameters to improve correlation. Steady-state simulations were run for the baseline and the solar control PVB configuration. Starting a drive from a full thermal soak condition is a fairly common situation.

\section{Cooldown Simulation}

Cooldown simulations were performed to determine the allowable increase in vent temperature due to the solar control PVB's reduction of thermal load. The primary differences between the steady-state and cooldown simulations are dashboard vent register flow, vehicle speed, and time-based changes in incident solar. The cooldown simulation consists of a 30-minute duration with the sun position and intensity starting at 11:45 MST on 9/10/11. 
The $\mathrm{A} / \mathrm{C}$ vent mass-flow rate was set to $0.136 \mathrm{~kg} / \mathrm{s}$, representing a high blower setting, and remained constant throughout the 30-minute cooldown. The internal heat transfer coefficients for the cooldown case were calculated by a separate CFD simulation and were then mapped to the RadTherm model. The heat transfer coefficients remained constant during cooldown. The baseline case used the $\mathrm{A} / \mathrm{C}$ vent temperature profile shown in Figure 4.

The environmental parameters varied across the 30-minute cooldown (e.g., solar direction, wind speed, etc.); however, the ambient temperature was held constant at $35^{\circ} \mathrm{C}$. In addition, the simulation assumed that the vehicle was travelling at a speed of $48 \mathrm{mph}(77 \mathrm{kph})$ with a heading of due south. This is the average speed of the U.S. Environmental Protection Agency Highway Fuel Economy drive cycle. These conditions were selected to provide a representative hot case and exterior velocity. This is the type of weather that drivers would use the $\mathrm{A} / \mathrm{C}$. If the ambient temperature or solar were lower, the $\mathrm{A} / \mathrm{C}$ might not be used. The weather conditions selected are consistent with the vent temperature profile in Figure 4 and $\mathrm{A} / \mathrm{C}$ power profile in Figure 9.

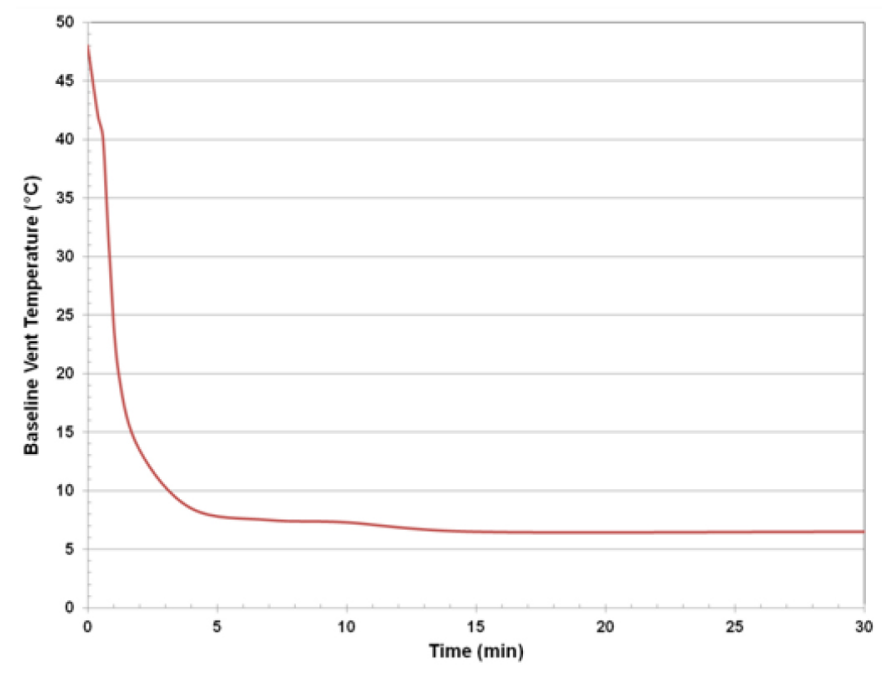

Figure 4. Baseline A/C vent temperature profile

The approach used in this analysis was to achieve an equal performance metric for baseline and solar control PVB configurations after 30 minutes of cooldown. Three metrics were considered to quantify the impact of reducing the vehicle interior temperatures and thermal load:

Volume average air temperature. A challenge of using the volume average air temperature as the performance metric is that the air temperature changes rapidly due to the inflow of cool air from the $\mathrm{A} / \mathrm{C}$ system and the low thermal mass of the interior air. Plus when occupants enter a vehicle, some air exchange occurs with the ambient. After 30 minutes of cooldown, the impact on the air temperature is very small in the analysis. This metric will underestimate the impact of solar load reduction technologies since the interior mass of the vehicle impacts thermal comfort and $\mathrm{A} / \mathrm{C}$ use. In addition, the simplified 12-node air model tends to smooth out the temperatures and would not be as accurate as a full CFD analysis.

Average interior mass temperature. The mass average temperature $\left(\mathrm{T}_{\text {mass }}\right)$ is calculated by multiplying temperature $\left(T_{i}\right)$ by its mass $\left(m_{i}\right)$. The sum of the mass temperatures $\left(\mathrm{T}_{\mathrm{i}} \mathrm{m}_{\mathrm{i}}\right)$ is then divided by the sum of the masses.

$$
\overline{\mathrm{T}}_{\text {mass }}=\frac{\sum\left(T_{i} \times m_{i}\right)}{\sum m_{i}}
$$

To achieve equal average interior mass temperatures for the solar control PVB configuration, the $\mathrm{A} / \mathrm{C}$ vent temperature was increased by a uniform amount at each time point. The amount that the vent temperature was raised was iterated upon until the mass average temperatures at 30 minutes were equal to the baseline case. The interior mass average temperature fully accounts for the reduced interior temperatures, but it tends to overestimate the effect of the reduction that the occupant would feel.

Occupant thermal comfort. The ideal solution would be to perform a thermal comfort analysis that would include both the effects of the cool $\mathrm{A} / \mathrm{C}$ air as well as the effects of hot interior surfaces on the occupant. However, this more involved analysis was beyond the scope of this project.

To reduce errors, volume average air temperature and average interior mass temperature performance metrics were combined to estimate the reduction in $\mathrm{A} / \mathrm{C}$ capacity and compressor power.

Increasing the vent temperature was the selected method of decreasing $\mathrm{A} / \mathrm{C}$ system capacity. It was assumed that an automatic temperature control system would adjust the vent temperature higher due to the lower initial temperature and lower solar gain during the drive. Another way is to reduce the air flow rate (blower setting). In a real-world case, some combination of the two methods would be used, with the driver reducing the blower setting or increasing the temperature set point. For this analysis, increasing the vent temperatures was much easier to achieve because reducing the air flow would have required re-running the CFD case to obtain updated interior heat transfer coefficients.

\section{RadTherm Steady-State Results}

The baseline glass configuration analysis temperatures in Figure 5 compared favorably to the test data. The most important locations (air, dashboard, windshield) matched well. 


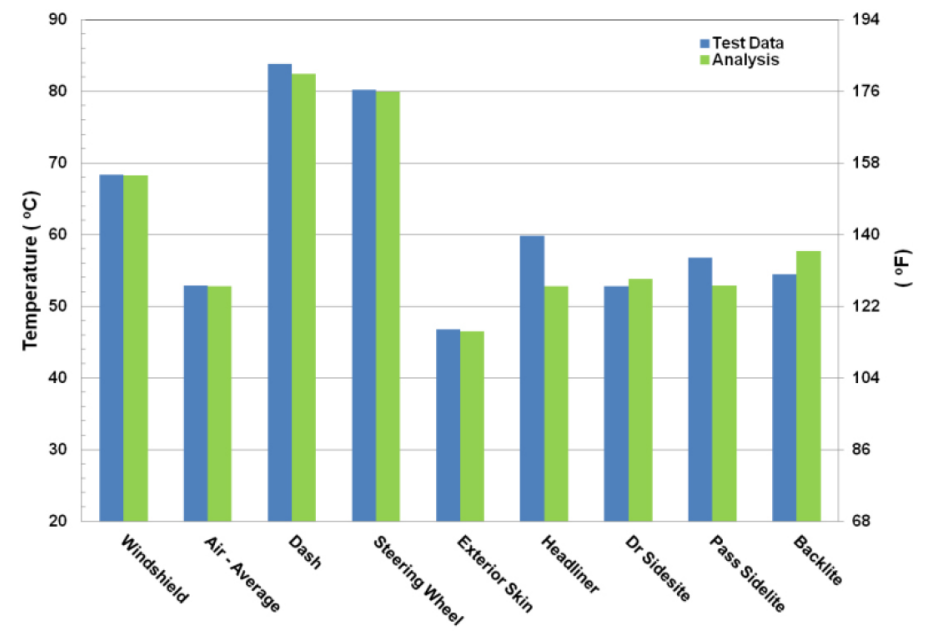

Figure 5. Baseline comparison of analysis temperature results to test data

The solar control PVB windshield model was run, and the change in temperature between solar absorbing PVB and baseline configurations was calculated. These temperature reductions were then compared to the changes in temperature measured during the test. Figure 6 shows the results for the solar control PVB windshield.

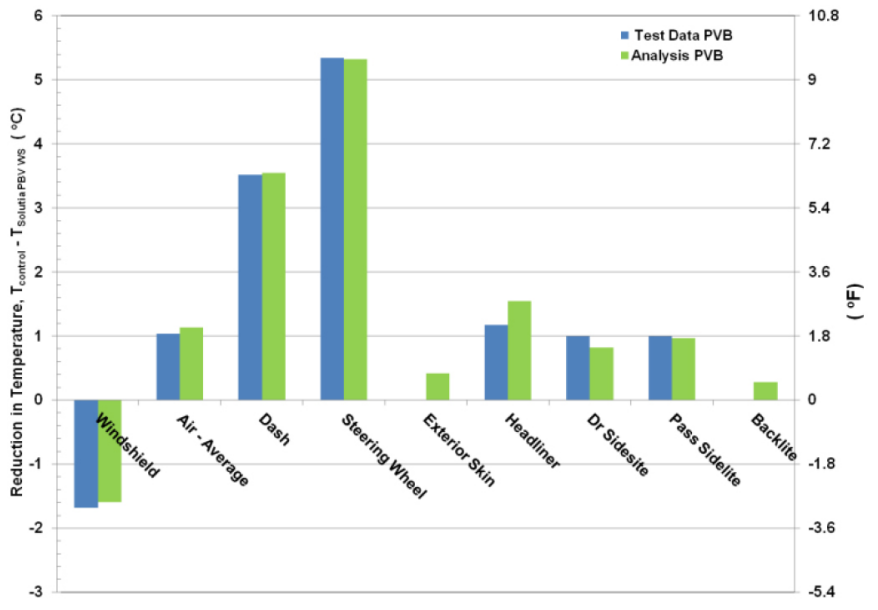

Figure 6. Reduction in temperature for the solar control $P V B$ windshield

As expected, the windshield was warmer than baseline (negative temperature reduction) because the solar control PVB had higher absorptivity. All of the other results are within $0.5^{\circ} \mathrm{C}$ of test data except for the front right seat.

The significance of these results is:

1. The steady-state simulation yielded accurate temperature and resulted in initial temperatures for the cooldown model.

2. Changing the optical properties in the model resulted in changes in temperatures that were very close to the test results.

\section{RadTherm Cooldown Results}

Figure 7 shows the average interior mass temperature for the two configurations. As can be seen in the figure, the initial average interior mass temperature is $1.1^{\circ} \mathrm{C}$ lower for the configuration with solar control PVB. To achieve equal mass average interior mass temperature at 30 minutes, the $\mathrm{A} / \mathrm{C}$ vent temperature was increased by $2.3^{\circ} \mathrm{C}$ for the configuration with the solar control PVB windshield.

As discussed in the Cooldown Simulation Section, using the average interior mass temperature alone will overestimate the impact of solar control PVB. Interior air temperature most certainly impact occupant thermal comfort and the control of the $\mathrm{A} / \mathrm{C}$. Therefore the vent temperature increase for the volume average air temperature method (essentially $0^{\circ} \mathrm{C}$ ) was averaged with the $2.3^{\circ} \mathrm{C}$ vent temperature increase from the average interior mass method to yield a $1.2^{\circ} \mathrm{C}$ increase in vent air temperature.

A 30-minute cooldown was originally selected because the average interior mass temperature was beginning to stabilize at the end of the time period. To be consistent with the duration of the compressor power profile and duration of the vehicle simulations, a 20-minute duration should have been used. This would have resulted in a larger increase in vent temperature; therefore, the authors chose to use the more conservative 30-minute duration.

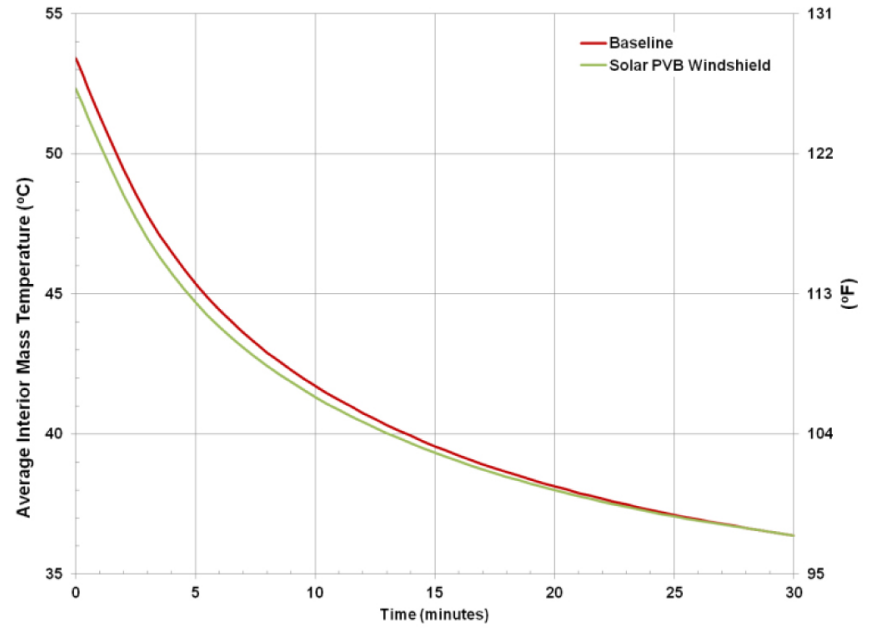

Figure 7. Average interior mass temperature at $35^{\circ} \mathrm{C}$ ambient temperature

\section{A/C System Capacity Analysis}

A thermal model was developed in Engineering Equation Solver (EES) to quantify the impact of higher vent temperatures on the $\mathrm{A} / \mathrm{C}$ evaporator capacity. The analysis accounts for latent and sensible cooling loads integrated across the cooldown profile (Figure 4). Equation 2 is an energy balance calculation of the air side of the evaporator 
where $\dot{Q}_{c v}$ is evaporator load, $\dot{m}_{a}$ is the mass-flow rate of dry air, $h$ is the enthalpy, and $\omega$ is humidity ratio. A subscript of $a$ is used for air, $v$ for vapor, $l$ for liquid, 1 is the condition at the inlet, and 2 is at the exit.

$$
\dot{Q}_{c v}=\dot{m}_{a}\left[\left(h_{a_{2}}-h_{a_{1}}\right)+\left(\omega_{1}-\omega_{2}\right) h_{l_{2}}+\omega_{2} h_{v_{2}}-\omega_{1} h_{v_{1}}\right]
$$

Next, the percent reduction in evaporator capacity $(\theta)$ was determined for each configuration as shown in Equation 3.

$$
\theta=\frac{\dot{Q}_{\text {baseline }}-\dot{Q}_{\text {modified }}}{\dot{Q}_{\text {baseline }}} * 100 \%
$$

The mass flow rate of the mixture into the evaporator was assumed to be $0.136 \mathrm{~kg} / \mathrm{s}$, equivalent to the flow used during RadTherm analysis. This is representative to $\mathrm{A} / \mathrm{C}$ blower speed of approximately $250 \mathrm{cfm}$. A 100\% outside air blower setting was also assumed for modeling purposes. The exit air temperature profile for the baseline case, shown in Figure 4, was increased $1.2^{\circ} \mathrm{C}$ at each time point for the solar control PVB. The inlet air was assumed to be $35^{\circ} \mathrm{C}$ to be consistent with the RadTherm analysis. The atmospheric pressure was assumed to be at sea level, or $101.4 \mathrm{kPa}$, and dry air was modeled as an ideal gas. Because the reduction in capacity is fairly small, it is reasonable to assume the $\mathrm{A} / \mathrm{C}$ system would operate similarly in the baseline and solar control PVB case. Therefore, it was assumed that the coefficient of performance (COP) in all cases was the same and that the percent reductions in $\mathrm{A} / \mathrm{C}$ capacities and compressor powers were equivalent.

Reduction in $\mathrm{A} / \mathrm{C}$ capacity for the solar control PVB configuration is shown in Figure 8. The results show that the impact of the advanced solar control technologies on $\mathrm{A} / \mathrm{C}$ capacity decreases as relative humidity increases. In high humidity environments, a larger portion of the evaporator capacity goes to condensing moisture.

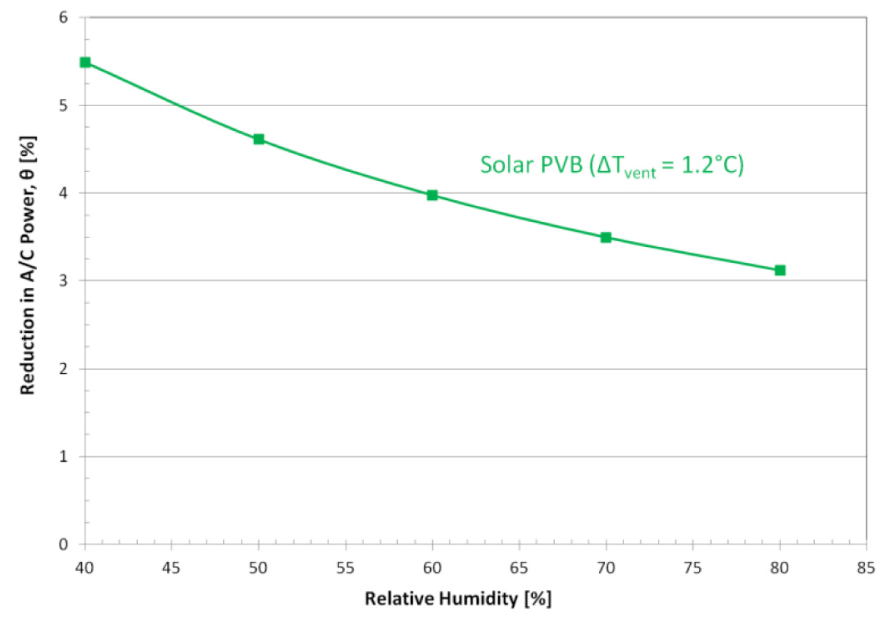

Figure 8. A/C model results - \% reduction in $A / C$ power

\section{VEHICLE SIMULATION}

\section{A/C Power vs. Time Profile for the Vehicle Simulation}

A literature survey was conducted in reference [4] to develop a representative $\mathrm{A} / \mathrm{C}$ load profile for a vehicle simulation. The climate control load was divided into two parts:

1. Transient - After a thermal soak, the climate control load was characterized by a high initial value that decreased with time. An example is entering a hot vehicle after it has been parked in the sun, driving, and having the $\mathrm{A} / \mathrm{C}$ on with maximum blower airflow to cool the interior. Vehicles have different transient times due to a variety of factors based on manufacturer design choices. We selected 10 minutes as a representative transient duration.

2. Steady State - During steady state, the impact of the thermal soak was diminished. The climate control system maintained the thermal conditions in the passenger compartment. An example is driving down the interstate and having moderate temperature and blower settings.

Table 4 shows the range of vehicle types, environments, and $\mathrm{A} / \mathrm{C}$ systems from a variety of sources that we considered.

Table 4. Cooling load data sources

\begin{tabular}{|l|c|c|c|}
\hline Source & Vehicle & Environment & A/C \\
\hline $\begin{array}{l}\text { SAE } \\
\text { ARCRP [5] }\end{array}$ & $\begin{array}{c}\text { N/A, } \\
\text { bench data }\end{array}$ & hot & mechanical \\
\hline ANL [6] & small EV & moderate & electrical \\
\hline NREL [7] & Prius & hot & electrical \\
\hline Ford [8] & Fusion & hot & electrical \\
\hline ANL [6] & $\begin{array}{c}\text { Mercedes } \\
\text { S400 }\end{array}$ & moderate & electrical \\
\hline Visteon [9] & $\begin{array}{c}\text { midsized } \\
\text { SUV }\end{array}$ & hot & mechanical \\
\hline
\end{tabular}

The data from these sources were averaged to create an $\mathrm{A} / \mathrm{C}$ compressor power profile. The 10-minute transient load was applied to the model as a linear decay from a peak power of $3.89 \mathrm{~kW}$ at the start of the drive to a $2.10-\mathrm{kW}$, steady-state load. This equates to an average transient load of $2.99 \mathrm{~kW}$ for the 10-minute period. Additionally, an electric condenser fan was assumed to draw $150 \mathrm{~W}$ during the 10 -minute transient and $50 \mathrm{~W}$ during the steady-state period. A $150-\mathrm{W}$ heating, ventilating, and $\mathrm{A} / \mathrm{C}$ (HVAC) blower load was assumed constant for the vehicle simulation.

The composite $\mathrm{A} / \mathrm{C}$ power profile, including the compressor, condenser fan, and HVAC blower, is shown in Figure 9. The intention of this profile is to define a reasonable hot environment compressor power for the FASTSim model. This profile was not a result of the RadTherm thermal model. The RadTherm model and A/C system capacity analysis results were used to define a potential increase in vent 
temperature and respective decrease in $\mathrm{A} / \mathrm{C}$ power due to the thermal load reduction.

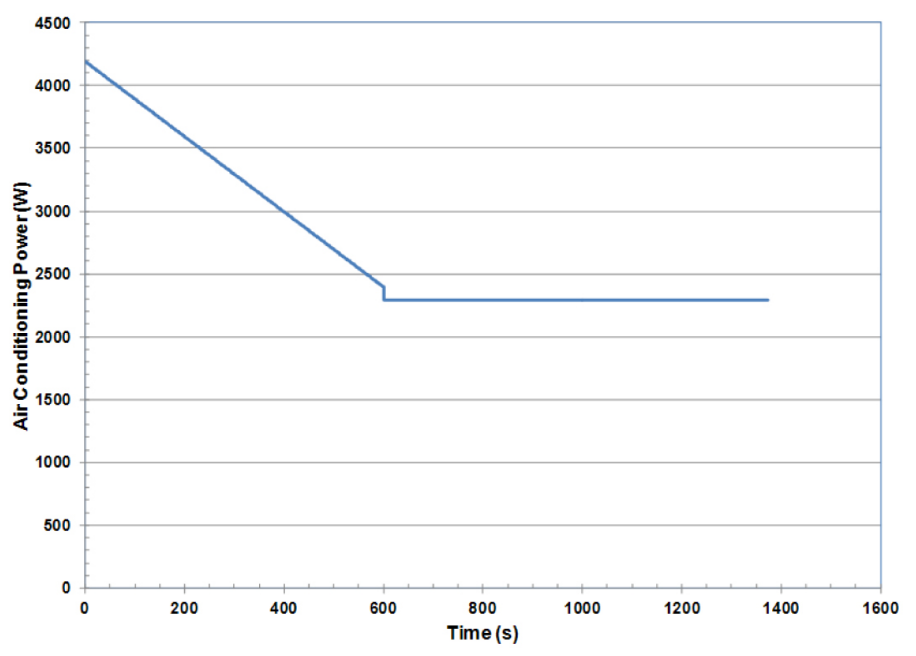

Figure 9. A/C power curve for the baseline vehicle simulation

\section{FASTSim Analysis}

NREL used validated conventional vehicle, PHEV, and EV models to determine the effect of $\mathrm{A} / \mathrm{C}$ loads on fuel economy and electric range. The impact is measured on both the city and highway drive cycles. For each powertrain type, we applied the baseline A/C power vs. time curve in Figure 9. For vehicle simulations that extended beyond 20 minutes, the steady-state $\mathrm{A} / \mathrm{C}$ power was applied to the end of the simulation. We then parametrically reduced the $\mathrm{A} / \mathrm{C}$ compressor power while keeping the condenser fan and HVAC blower loads the same. For comparison purposes, we have included a "no A/C" case where we assume only the blower was operated.

The Future Automotive System Technology Simulator (FASTSim) is an Excel, power-based model that uses vehicle- and component-specific parameters to predict performance. It back-calculates the power demanded from the engine and/or battery to overcome drag, acceleration, ascent, rolling resistance, and inertia for a specified drive cycle. Battery, electric motor, and engine component models match well with detailed component models included in vehicle simulation software such as PSAT and ADVISOR. The model includes energy management strategies and accounts for regenerative braking as well as auxiliary loads.

Table 5 lists the essential parameters of the Toyota Camry, Chevrolet Volt, and Nissan Leaf. These vehicles served as the conventional vehicle, PHEV, and EV, respectively, used in this analysis
Table 5. Vehicle- and component-specific parameters

\begin{tabular}{|l|c|c|c|}
\hline & 2012 Camry & 2012 Volt & 2012 Leaf \\
\hline Vehicle & & & \\
$\mathrm{C}_{\mathrm{d}}$ & 0.28 & 0.29 & 0.29 \\
Frontal area $\left(\mathrm{m}^{2}\right)$ & 2.14 & 2.06 & 2.19 \\
\hline Engine & & & \\
Power $(\mathrm{kW})$ & 132.7 & 62 & -- \\
\hline Traction Battery & & & \\
Power $(\mathrm{kW})$ & - & 119.4 & 90 \\
Capacity $(\mathrm{kWh})$ & - & 16 & 24 \\
\hline Motor & - & 111 & 80 \\
Power $(\mathrm{kW})$ & 700 & 300 & 300 \\
\hline Accessory Load & & & \\
Power (W) & & & \\
\hline
\end{tabular}

Each FASTSim vehicle model was validated within $10 \%$ of published performance metrics. Table 6 compares simulated results to published/reported performance metrics. The simulated energy use of the PHEV was validated in both charge-depleting (CD) and charge-sustaining (CS) modes. $\mathrm{CD}$ is the mode of vehicle operation associated with the operation of an EV or the start up of a PHEV when fully charged. During this mode, power is primarily sourced from the battery, with the engine providing supplemental power when necessary. When the battery of the PHEV depletes to its minimum state of charge, it enters CS mode, where regenerative braking and the power plant work to maintain that state of charge as necessary.

Table 6. Validation of Toyota Camry, Chevrolet Volt, and Nissan Leaf in FASTSim

\begin{tabular}{|l|c|c|c|}
\hline & Reported & Simulated & $\begin{array}{c}\text { Percent } \\
\text { Difference }\end{array}$ \\
\hline $\begin{array}{l}\text { 2012 Camry } \\
\text { (Conventional) } \\
\text { Fuel economy (mpg) }\end{array}$ & 28.7 & 28.0 & $2 \%$ \\
\hline $\begin{array}{l}\text { 2012 Volt (Plug-in } \\
\text { Hybrid) }\end{array}$ & 37 & 39.7 & $7 \%$ \\
\hline $\begin{array}{l}\text { CS combined } \\
\text { city/hwy (mpg) }\end{array}$ & 0.36 & 0.369 & $3 \%$ \\
\hline $\begin{array}{l}\text { CD combined } \\
\text { city/hwy (kWh/mile) }\end{array}$ & 35 & 33.4 & $5 \%$ \\
\hline CD range (miles) & 0.34 & 0.35 & $3 \%$ \\
\hline $\begin{array}{l}\text { 2012 Leaf (Electric) } \\
\text { Electric consumption } \\
\text { (kWh/mile) }\end{array}$ & & & \\
\hline
\end{tabular}

Figure 10, Figure 11, and Figure 12 present the parametric results for the conventional vehicle, PHEV, and EV. These curves can be used to assess the impact of any technology that reduces the thermal load and compressor power.

For the conventional vehicle, a reduction in $\mathrm{A} / \mathrm{C}$ load resulted in an increase in fuel economy. The blue curve represents fuel economy results on the unadjusted city (UDDS) cycle while the red curve represents fuel economy results on two 
unadjusted highway (hwy) cycles. The duration of the UDDS cycle was 22.9 minutes while the duration of the two highway cycles was 25.5 minutes. These durations are close to the average commute travel time of 22.85 minutes for the United States [10]. An implication of the cycle durations is that the analysis approximately equally weights the impact of the transient and steady-state compressor powers.

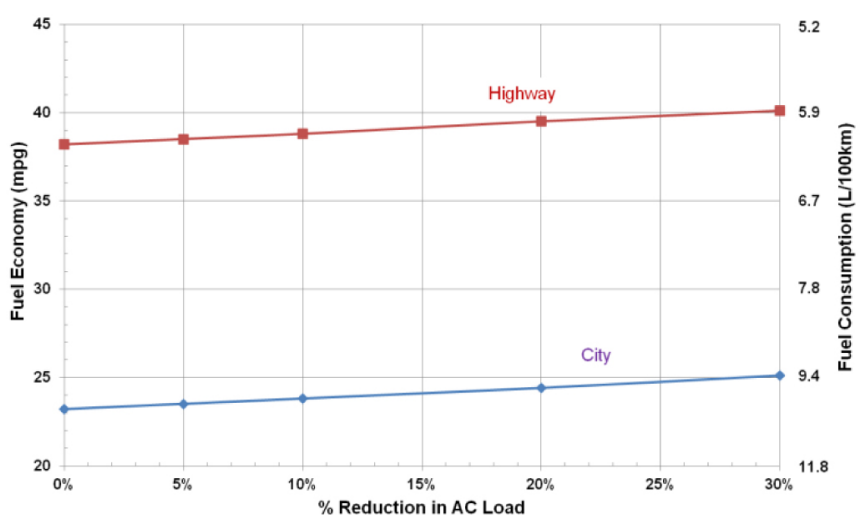

Figure 10. Impact of $A / C$ load reduction on fuel economy - conventional vehicle

To simulate real world PHEV operation, we combined and adjusted city/highway results. Similar to the conventional vehicle, fuel economy increased with lower A/C loads. For the $\mathrm{EV}$, a reduction in $\mathrm{A} / \mathrm{C}$ load resulted in increased range. For both the PHEV and EV, multiple back-to-back cycles were performed for charge balancing for the PHEV and determining total range for the EV. This results in a heavier weighting of the steady-state $\mathrm{A} / \mathrm{C}$ load.

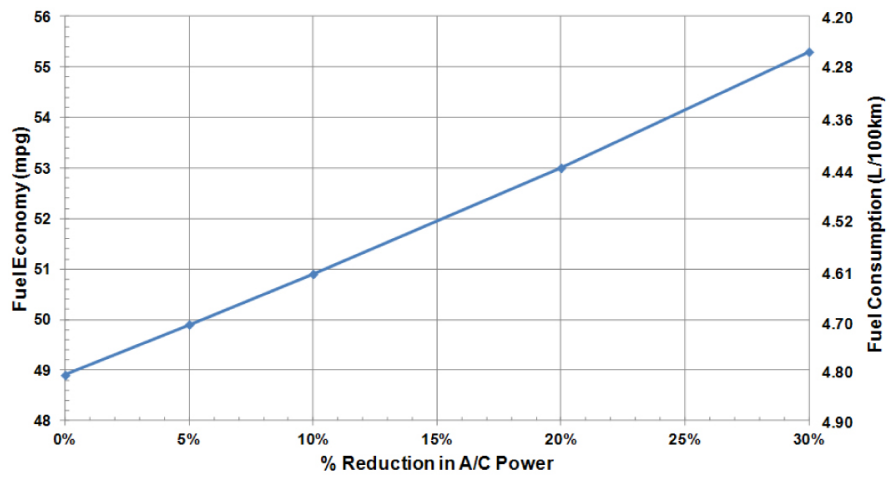

Figure 11. Impact of A/C load reduction on fuel economy - PHEV

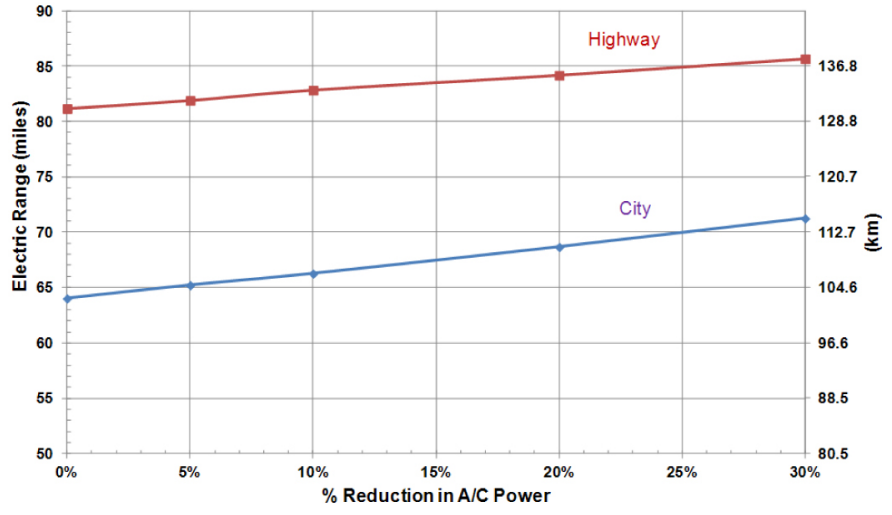

Figure 12. Impact of A/C load reduction on electric range - $E V$

\section{Combining the Solar Control PVB Results with the FASTSim Results}

In the RadTherm analysis that determined the increase in vent temperature due to the solar control PVB configuration, the ambient air temperature was $35^{\circ} \mathrm{C}$. This parameter strongly influenced the heat loss to the environment and the resulting required $\mathrm{A} / \mathrm{C}$ vent temperatures. A relative humidity of $60 \%$ was also assumed to provide a hot/humid environment representative of a reasonably severe operating condition. Using this humidity in Figure 8, the solar control PVB windshield resulted in a $4.0 \%$ reduction in $\mathrm{A} / \mathrm{C}$ power. These reductions in $\mathrm{A} / \mathrm{C}$ power were then applied to the data in Figure 10, Figure 11, Figure 12 to determine the impact on vehicle performance.

If a solar control PVB windshield were installed in an EV, the range could potentially increase 1.0 mile $(1.5 \mathrm{~km})$ on the city drive cycle and 0.6 mile $(1.0 \mathrm{~km})$ on the highway cycle during operation of the $\mathrm{A} / \mathrm{C}$ system. This was calculated by determining the range at $4.0 \% \mathrm{~A} / \mathrm{C}$ reduction and subtracting the range at $0 \% \mathrm{~A} / \mathrm{C}$ reduction (baseline $\mathrm{A} / \mathrm{C}$ load) in Figure 12 .

For the conventional vehicle (Figure 10), the solar control PVB windshield increased the city and highway fuel economy by $0.3 \mathrm{mpg}$ during the operation of the $\mathrm{A} / \mathrm{C}$ system.

The PHEV combined adjusted fuel economy (Figure 11) increased $0.8 \mathrm{mpg}$ due to the solar control PVB windshield. Summaries of the results are shown in Table 7, Table 8, and Table 9.

Table 7. Impact of solar absorbing PVB - summary of thermal results

\begin{tabular}{|c|c|c|}
\hline $\begin{array}{c}\text { Reduction in } \\
\text { Average Air Temp } \\
\left({ }^{\circ} \mathrm{C}\right)\end{array}$ & $\begin{array}{c}\text { Increase in A/C } \\
\text { Vent Temp } \\
\left({ }^{\circ} \mathrm{C}\right)\end{array}$ & $\begin{array}{c}\text { Reduction in } \\
\text { A/C Capacity } \\
\text { and Power }(\%)\end{array}$ \\
\hline 1.0 & 1.2 & 4.0 \\
\hline
\end{tabular}


Table 8. Impact of solar absorbing PVB - summary of vehicle results (metric units)

\begin{tabular}{|c|c|c|c|c|}
\hline \multicolumn{2}{|c|}{$\begin{array}{c}\text { EV Range Increase } \\
(\mathbf{k m})\end{array}$} & $\begin{array}{c}\text { Conventional Vehicle } \\
\text { Change in Fuel } \\
\text { Consumption } \\
\text { (L/100 km) }\end{array}$ & $\begin{array}{c}\text { PHEV Change in } \\
\text { Combined Fuel } \\
\text { Consumption } \\
\text { (L/100 km) }\end{array}$ \\
\hline City & Hwy & City & Hwy & \\
\hline 1.5 & 1.0 & -0.108 & -0.041 & -0.082 \\
\hline
\end{tabular}

Table 9. Impact of solar absorbing PVB - summary of vehicle results (English units)

\begin{tabular}{|c|c|c|c|c|}
\hline \multicolumn{2}{|c|}{$\begin{array}{c}\text { EV Range } \\
\text { Increase } \\
\text { (miles) }\end{array}$} & $\begin{array}{c}\text { Conventional Vehicle } \\
\text { Change in Fuel } \\
\text { Economy } \\
\text { (mpg) }\end{array}$ & $\begin{array}{c}\text { PHEV Change in } \\
\text { Combined Fuel } \\
\text { Economy } \\
\text { (mpg) }\end{array}$ \\
\hline City & Hwy & City & Hwy & \\
\hline 1.0 & 0.6 & 0.3 & 0.3 & 0.8 \\
\hline
\end{tabular}

The percent increase in EV range and fuel economy are shown in Table 10.

Table 10. Impact of solar absorbing PVB - percent increase in $E V$ range and fuel economy

\begin{tabular}{|c|c|c|c|c|}
\hline \multicolumn{2}{|c|}{ EV - Range } & \multicolumn{2}{c|}{$\begin{array}{c}\text { Conventional } \\
\text { MPG }\end{array}$} & $\begin{array}{c}\text { PHEV } \\
\text { MPG }\end{array}$ \\
\hline City & Hwy & City & Hwy & \\
\hline $1.5 \%$ & $0.7 \%$ & $1.1 \%$ & $0.7 \%$ & $1.7 \%$ \\
\hline
\end{tabular}

Any technology that reduces air and surface temperatures during a thermal soak or cooldown in a similar manner would have similar $\mathrm{A} / \mathrm{C}$ power reduction and vehicle performance results.

\section{SUMMARY/CONCLUSIONS}

The objective of the project was to assess the impact of a solar control PVB windshield on vehicle fuel economy and EV range. The approach included outdoor vehicle thermal soak testing, RadTherm cooldown analysis, and vehicle simulations. Outdoor thermal soak tests were conducted at NREL. Measureable reductions in interior temperatures were observed due to the installation of a solar control PVB windshield. The average interior air temperature dropped $1^{\circ} \mathrm{C}$ while the dashboard surface temperature dropped $3.5^{\circ} \mathrm{C}$. Thermal analyses and vehicle simulations were performed to determine the impact of the reduction in temperatures on $\mathrm{A} / \mathrm{C}$ capacity, A/C power, vehicle fuel use, and electric range. Due to the incorporation of the solar control PVB windshield, the A/C system capacity could be reduced $4 \%$ which improved the conventional vehicle fuel economy by $0.7 \%$ to $1.1 \%$ and EV range by $0.7 \%$ to $1.5 \%$ depending on the drive cycle.

Critical assumptions included ambient temperature, ambient humidity, A/C control strategy, drive cycle, and vehicle type. Although real-world fuel use and range will be different, these analyses provide an estimate of the magnitude of the impact of solar load reduction glass. The improvement in occupant thermal comfort from lower interior temperatures following a thermal soak would be realized in the real world but was not quantified in this project. Advanced solar control technologies that reduce the thermal loads during soak and cooldown are part of the system solution to reduce the impact of climate control on vehicle fuel economy and range.

\section{REFERENCES}

1. Farrington, R.; and Rugh, J. "Impact of Vehicle Air Conditioning on Fuel Economy, Tailpipe Emissions, and Electric Vehicle Range," NREL paper \# CP-540-28960, Earth Technologies Forum, Washington, DC., October 2000.

2. Rugh, J.; Hendricks, T.; and Koram, K. "Effect of Solar Reflective Glazing on Ford Explorer Climate Control, Fuel Economy, and Emissions," Proceedings of the International Body Engineering Conference, Paper \# 2001-01-3077, Society of Automotive Engineers, Detroit, MI.

3. Rugh, J., Chaney, L., Lustbader, J., and Meyer, J., "Reduction in Vehicle Temperatures and Fuel Use from Cabin Ventilation, Solar Reflective Paint and a new Solar Reflective Glazing," SAE Technical Paper 2007-01-1194, 2007, doi:104271/2007-01-1194.

4. Barnitt, R.; Brooker, A.; Ramroth, L.; Rugh, J.; Smith, K. "Analysis of Off-Board Powered Thermal Preconditioning in Electric Drive Vehicles." 25th World Battery, Hybrid and Fuel Cell Electric Vehicle Symposium \& Exhibition, Shenzen, China, Nov. 2010.

5. Society of Automotive Engineers. Cooperative Research Program: Alternative Refrigerant Project Phase I. July 14, 2003. (Draft final report - unpublished).

6. Lohse-Busch, H.; "Small EV Testing and Analysis." Presentation to the U.S. Department of Energy. Argonne National Laboratory November 17, 2009.

7. Rugh, J. "Impact of Sungate EP on PHEV Performance: Results of a Simulated Solar Reflective Glass PHEV Dynamometer Test." NREL Report No. TP-540-45908. Golden, CO: National Renewable Energy Laboratory, 2009; $32 \mathrm{pp}$.

8. Maranville, C. Personal email. Ford Fusion cooling load. Ford Motor Company, June 4, 2010.

9. Meyer, J. A/C Cooling Load data. Visteon Corporation, March 1, 2007.

10. Santos A.; McGuckin, N.; Nakamoto, H.Y.; Gray, D.; and Liss, S. "Summary of Travel Trends: 2009 National Household Travel Survey," Report \# FHWA-PL-11-022, U.S. Department of Transportation, June 2011. 


\section{CONTACT INFORMATION}

John P. Rugh

National Renewable Energy Laboratory

15013 Denver West Parkway

Golden, Co 80401

john.rugh@nrel.gov

Matt Rose

Eastman Chemical

575 Maryville Centre Drive

St. Louis, MO 63141

(314) 674-1248

mmrose@eastman.com

\section{ACKNOWLEDGMENTS}

The authors gratefully acknowledge the support for NREL's vehicle climate control load reduction work provided by Lee Slezak, David Anderson, and Patrick Davis in the Vehicle Technologies Program of the U.S. Department of Energy's Office of Energy Efficiency and Renewable Energy.

The test program and application of existing NREL thermal and vehicle models was funded by Eastman Chemical Inc. who also provided the test materials and window property data.

The Engineering Meetings Board has approved this paper for publication. It has successfully completed SAE's peer review process under the supervision of the session organizer. This process requires a minimum of three (3) reviews by industry experts. ISSN 0148-7191
Positions and opinions advanced in this paper are those of the author(s) and not necessarily those of SAE. The author is solely responsible for the content of the paper.

SAE Customer Service:

Tel: 877-606-7323 (inside USA and Canada)

Tel: 724-776-4970 (outside USA)

Fax: 724-776-0790

Email: CustomerService@sae.org

SAE Web Address: http://www.sae.org

Printed in USA 